\title{
Book Presence and Feline Absence: A Conversation with Mark Z. Danielewski
}

Kári Driscoll and Inge van de Ven

Since the publication of his monumental début novel, House of Leaves in 2000, Mark Z. Danielewski has emerged as one of the great champions of the book as artifact in the twenty-first century. His latest project, The Familiar, is set to comprise twenty-seven volumes total, and, judging by the five volumes that have been published so far, will likely run to over 20,000 pages. On a cold night in December 2016, we sat down for a Skype conversation with Danielewski. We spoke with him about the state of the art of print and all things bookish in a digital age. We invited him to reflect on the apocalyptic predictions of the demise of the book, on the unique pleasures of reading print literature, the advantages and disadvantages of e-books for life, the signiconic, and visual culture. And the ways in which the digital renews the reading experience of print books, in terms of affect and tactility. We were especially interested in hearing his opinions on the monumentality of the book as a durable and resilient medium, in terms of the newly apparent materialities of literature, particularly in the context of his Familiar project, which raises questions concerning the extravagant demands he places on his readers in terms of effort, time, and shelf space. Along the way, we talked about binge reading, collective intelligence, technical difficulties, and reading code. And of course: what's up with all the cats?

KD: I think it's fair to say that ever since House of Leaves you've been one of the great proponents of print as a medium. At the same time, you've also been at the forefront of using the internet as a digital paratext to the physical novel, in the shape of the House of Leaves forum. So we wanted to have a conversation with you about where you think the book is at, right now, and where you see yourself in relation to the place of the book in the digital age. 
MZD: I don't disagree with what you've said, though I wouldn't characterize myself as a proponent of print. But it is curious that, even as I continue to publish new works, I seem to create books that are inherently averse to a digital experience and by contrast loved more as a print experience. My publisher informs me that, where most authors sell about thirty percent of their books digitally now, my books sell around three percent digitally. You can buy The Familiar now as a digital, pdf experience. But readers seem to enjoy the tactile experience. Is this because a lot of the readers of The Familiar are readers of House of Leaves and Only Revolutions, and in a certain way predisposed? That's possible, but that's not entirely true. Maybe they are older, so they're used to print, so they gravitate toward that experience? That's not necessarily true either, because there are a lot of younger readers. So I'm not sure. But it's certainly true that I pay a great deal of attention to how the book is created, going so far as to build phonebooks in order to experience what 880 pages feel like, and how thick or thin the paper should be so it's manageable. Even the weight is important. As I'm writing about this tiny insubstantial cat, who is the absent feline at the beginning of this tale, I like the counterweight, the heaviness, the tactile communication of weight and size. That's a brief sketch of why I think that's the case. What do you both think?

IV: In many ways, this is an old question that keeps resurfacing. In 1975, Ulises Carrión described the book as not merely a container of words but as a sequence of spaces and, perhaps more importantly, a sequence of moments, an autonomous "space-time sequence" $(1980,8)$. What Carrión called "The New Art of Making Books" is really the making of an autonomous and self-sufficient form, with a text that emphasizes that form is an organic part of it. This seems like a description of some of your works, like House of Leaves, Only Revolutions, and now The Familiar. Maybe readers intuit this and are drawn to the monumental form of these works as autonomous space-time sequences that allow them momentarily to flee the hectic, information-intensive everyday?

MZD: It does seem that way. I wonder how much of the book is rooted in my reputation, my overall work. Literally and physically, House of Leaves puts the scattering and assemblage of leaves in the forefront. It's all about the construction of the book and the destruction of the book. But why though should that hold true for The Familiar? I'm not sure. Because those numbers aren't changing, even as now new readers enter. Let's say 
it was a group that had heard about it, and didn't want to read it digitally. Why isn't that percentage climbing? Do you think it is the readers? IV: In the case of The Familiar, I think notions of size, materiality, and monumentality are all interrelated. We often assume a correlation between quantity and quality. In everyday language we do this habitually, using terms like "great," "grand," "magnificent." So we see and feel the material characteristics of weight, length, bulk, size, page numbers, and expect them to be indicators of the book's contents, its conceptual magnitude. Marketers of books know this and appropriate these monumental aspects as a strategy to create value. And it works. I'm sure I'm not the only reader who is very much looking forward to having The Familiar's twenty-seven volumes properly displayed in my bookcase ... KD: Steel-reinforced shelves ... .

IV: Exactly. E-books obviously do not have this added benefit of demonstrating symbolic capital, this "weighty" quality that is both literal and figural. And of course there is the matter of canonization, which includes the way that people like us, academics and teachers of literature, use your novels in class. We are complicit. Whether you like it or not, you have been appropriated as one of a handful of contemporary authors who are currently reinventing the book-bound novel.

MZD: Here's a broader question: What does tracing out the differences between digital and print ultimately give us? What does that actually tell us about literature?

IV: I think we live under the assumption that the work changes with its material instantiations. The book, the e-book, the scroll, or the app: these are more than simply carriers of information, they determine how we write, how we create. In this respect, Only Revolutions becomes a separate work, rather than just a different version of the same work, when it is adapted to the e-book format. Its materiality and visual design are such an integral and indispensable part of its overall meaning and quality, they are fully integrated into the narrative. The book is a container of the storyworld, yet at the same time I feel that it is contained by this world, if that makes sense. Shape and texture of book, page, and print all play into this dynamic. So it's not just a different version of the same work.

KD: In many cases, particularly with the epub format or on plain-text repositories like Project Gutenberg, there is a prevailing assumption that the text is really "just the words," that it's only about the content and not 
the form. One of the reasons that we wanted to have this conversation with you about book presence in a digital age is that from House of Leaves onward, and in your whole oeuvre, you have been invested in the form, rather than just the content. Perhaps it's not so much about print as such, but rather the materiality of the text, of literature.

MZD: As much as my work is made to show a kind of literary advocacy for a kind of form, the margins that differentiate these forms have become narrower. In the past we were just glad to see the same work, whether it was written on papyrus or clay or carved in stone. ${ }^{1}$ And the fact that that letter or the series of letters could communicate something that groups in different places and different times could agree upon was enough.

When I was in school, I studied under John Hollander, who's a formidable poet, and a close friend and ally (most of the time) of Harold Bloom's. The sentiment there was that paying any attention to the visual is a kind of idolatry of text. It's to hold up these golden calves of importance and to miss the fact that it's what's beyond the serif, and the design, and the colors that matters. So that how language lived on a page was irrelevant and it should be immaterial. I don't think I have an answer to whether or not John Hollander was right. Certainly he was experimenting as well with concrete poetry. But I think his reservations resonated in me in a positive way, in that I'm exploring if that in fact is true.

Again, we live in a day and age where the technology of creation and reproduction is so exact that it can take advantage of these small margins. And thanks to readers of my work and writers and thinkers of my work like yourselves, we can begin to see how much of a difference this makes. How much of a difference does it make if the fonts are varied, if there are different colors, if there's a typographical design? If there's a certain amount of graphic aggregation of text, creation of text, what I call the "signiconic": 2 this melding of a literary form and a visual form? And what does that reveal?

Strangely enough, this data on how few people are reading the digital is almost the best review I can ask for. It shows that there is a desire to have an experience with this book, that there is something there that is contained. There's a new kind of vessel there that's containing more of this experience than can be contained on a digital platform. But how we ultimately hold this work accountable is very difficult. Again, I have that one statistic. I have the comments from people who've read and written about it. Yet, even though House of Leaves was published sixteen years ago, it is still too early to tell what the effects of this will be. Is this just 
a fringe, experimental voyage or is there actually something substantial here that's taking root, that is making sense of the visual culture we inhabit as well as the literary culture?

IV: When Only Revolutions came out in 2006, you famously claimed that it was designed to be a book that "can't exist online" (Rich 2006). But now, ten years later, there is in fact an e-book version (2015c). To what extent do you feel that this is the time for an e-book of Only Revolutions and are there certain medium-specific potentialities of the e-book that only now are interesting enough for you to undertake such a feat?

MZD: That's a good question. I think the experience with the Only Revolutions e-book, in order for it to even commence, I had to let go of the idea that $\mathrm{we}^{3}$ were going to recreate the experience of the bound book. That took almost a year of doing nothing, just to let go of that idea that it has to be the same as the book. That three-dimensionality I recognized could not be experienced in the e-book. So starting off with that projectand it did turn into a project, quite a big one-we started with a loss. We basically agreed that we can't create this physical experience of watching the book, of watching the two characters get closer and closer together, for example, and then move past each other. But what we decided was, okay, we can offer something more that you couldn't get in the book, for instance the road signs. You can easily pick certain points throughout the book and find an explanation and help you along the trail of their journey. And then the big decision was to forego the first page talking to the last page visually on the page and just to present them side by side so that you could actually see how Sam and Hailey were very like two lanes of a highway. And then there were other bells and whistles that we could add. I think that was very exciting. It's still too early to tell how that experience will unfold for people.

Only Revolutions takes a great deal of investment on the reader's part. You need a lot of imagination. You need a lot of skill. One of the things I've been toying with recently as I'm finishing volume five of The Familiar is to actually create a kind of reader rating system that somehow alerts readers, like skiers, that you are on a difficult trail. Because I feel the way that books are currently presented, everyone assumes, or in some degree feels entitled to be able to read everything that's put out there. And I feel it's a disservice to people who are good readers, who spend a great deal of time reading difficult books and can make their way through hard texts. Only Revolutions is a very difficult book and it requires investment so that once you spend time with your copy and you've marked it with 
your notes, you become familiar with its patterns. It's a lot to ask that of readers. And I don't even know why they would necessarily want to go to the electronic version. So really, then, the electronic version is at present for new readers-unless they're scholars, right? And how do those readers find their way to my text, when most readers who are aware of me, however they're aware of me, seem predisposed to the print matter? So, they are probably the most experimental forms.

We made the mistake of the electronic book: in achieving all that we did, we limited ourselves to one platform, which was the Apple OS platform. Well, no professor, for whom this book is perfectly suited, can assign that to their students because it exists only on one platform. Electronic books can only be required reading if they appear across all platforms. So we basically threw ourselves out of that conversation by attempting to achieve all that we achieved. And that's disappointing, because in the end you realize just how unstable the digital platform is.

Maybe that's really the conversation, too. I think people, when they are addressing books that require rereading, that require notes, that enjoy rereadings, will probably move away from the digital. I've noticed that even myself. If I'm reading something that I feel is disposable I have no problem reading it on a tablet. But I've read a couple of scholarly books where I had a great time writing notes and highlighting, because I knew I could access those notes much more quickly and then I found that all of that notating was lost in some transition to another platform. So for me that was disheartening and I quickly reverted to print books.

KD: One of the premises of this book on Book Presence in a Digital Age is that reports of the death of the book have been greatly exaggerated and that we have in fact seen a range of innovative approaches to the physicality of the book. Including yours, but also more radical forms of book art, where the book is only a physical object and no longer designed to be read: it is demediated, to use Garrett Stewart's term. There is an obvious objection to this premise, however, that these are in fact symptoms of the imminent demise of the book.

IV: Like a swan song.

KD: Yes, that now people, yourself included, feel compelled to produce these monuments to the book as artifact, because we see it sailing off into the sunset. So in other words the renewed emphasis on book presence is fueled by a sort of mourning for the book as medium. Do you have a sense of this? 
MZD: I don't have any of this attachment. You know, I think mourning about the book is sort of silly. Everyone has been talking about the demise of the novel for centuries, and I'm fine with all of it. If at some point in time a blogger ends up winning the Nobel Prize for literature, that's fine. I have always opposed this idea that narratives need to be constrained by a certain form or format. Inherently, not because I've voiced my againstness, but simply because I'm constantly exploring and moving out-very much like a cat with territorial claims. What can this really contain and what can't it?

As an aside: I think we shouldn't resist what's occurring right now. Which is that, despite having all this wonderful technology, we still experience a lot of difficulties using it, as in this very Skype conversation. ${ }^{4}$ This is not unusual; we're no aberration. Only in commercials for these services is everything perfect. Most people when they're Skyping or whatnot are dealing with all these kinds of degradations. So the book has a long way to go still, because it's incredibly durable and it's incredibly resilient and its form as a package of time is also incredibly durable.

And that's where I'm in very scary, unknown territory. Granted, there are precedents. But to suddenly say to readers that I'm going to create twentyseven of these things, you know ... I am making an enormous demand on people's time. In some ways I'm limiting their choices and that could be seen as a positive thing, because sometimes it's nice not to have to make a choice. But in some regards it's a co-opting of their leisure time, if you will. The book is a handheld object that you would look at as being twenty to thirty hours of your time. Even though you held it and could instantly put it away and instantly open it, you knew the experience it was going to give you, it was a tactical kind of understanding. Therefore, I think it's still a very powerful vehicle for containing and distributing the narratives.

Talking about any of my books but The Familiar in particular, there is an immediate, quantifiable sense of what this thing is and how much time it's going to take, how much space it's going to require to store it, to display it. And yet at the same time, as radical as it is to create a tale that is encyclopedic in size, virtually, readers quickly become aware they can read a volume very quickly. The learning curve is steep. After reading the first two volumes, by the time people are in volume three or four it's a binge reading on a weekend. So then in some ways it becomes the same novel we've always had. It's much smaller, it's much fleeter than maybe looks led one to expect. 
So there's certainly the physical part that explores the cage of what the book is, the novel is, but then of course there's the material itself. What happens when we're exploring multiple voices? What happens when these voices have meta-observers that begin to participate and change in the shape of the "Narcons." How do we locate this familiar family structure of mother and father and daughter and two sisters and a cat? It's very simple. And yet, we have a stepfather, we have again sort of a wobbly nature to that format. Or we look at Luther's family, the kind of game that he inhabits. As we begin to analyze this relationship between Jinging and Tian $\mathrm{Li}-\mathrm{is}$ it mother-son? is it a sponsor ...? like, what kind of relationship is this? All these different relationships also have their correlating relationships to genre, whether it's magical realism, or on-your-shoulder realism, how all those various genres, like sci-fi or horror, etc., begin to play out within the confines of this one book or series of books. And in their refusal to choose one over the other we can begin to explore how a much different way of viewing the world can be achieved.

I think that is my constant quest, throughout all my books: to labor in the pursuit of an experience that a reader cannot have anywhere else. You can't ultimately finish the book and say, I want to see the movie. You know the movie is not going to be a replacement for this experience and nothing else is. And that's why you will keep returning to it, because no matter what scary movie you watch, there's something about what House of Leaves does that none of those other forms can match. I think there are plenty of examples of books that don't do that. People read them, they're excited, but once they see the movie they're happy just to stick with the movie or they had no desire to read the book in the first place.

The question of how narratives are told and what the vessels or cages are that hold them is probably central to this discussion. Certainly The Familiar is quite literally often about the cage: characters feeling caged by their identities, whether it's the color of their skin, the type of language they use. And maybe it's good to be in your cage. It's like you're safer in the cage than out in the wild, but how do we find that? We are in the cage of this planet Earth. That's very much the question of the novel as well. The cage provides us with something, it captures something and then it releases something. Probably that's the next step of this conversation: What is contained that can be shared, that can be transported, that can be then freed for the reader? And I think that is my ultimate relationship with the reader: to take this huge narrative cage, and ultimately free that 
narrative within themselves. That's the wonder of literature. To take the cage with the story and uncage the story in the name of the imaginative process that it releases within itself.

IV: What you just said reminds me very much of the character Anwar, the father in The Familiar, who is working on a computer program, Paradise Open, which contains a lot of interesting glitches. Is Paradise Open a metaphor?

MZD: It's more than a metaphor because actually the code itself has a kind of life. The code itself is an example of yet another language that can produce communication within the text. ${ }^{6}$ You're aware of that potential, which I think is probably the most important thing to impart when we look at texts, simply to understand their potential, that they are living things. That has not changed. When people look at text they understand that there is something impactful there. Even when they accept all the sudden legal jargon that's imposed upon them when they get a software update, we sort of do it knowing that we will never read all of those fine points, but at the same time we are aware that there is a potential impact in that agreement. Text has that. So on one level you see a page of code and you accept that there is something there, but then if you write code you can also look at it and begin to realize that it stirs to life an animal that's part of the zoo of The Familiar.

Maybe the question with the digital is also that at present it just duplicates what is on the page. And that's what we tried to avoid with Only Revolutions. But more robust systems in the future could potentially run those lines of code like a console. Your tablet would actually be kind of a co-conspirator in your reading, and the reader, though faced with thousands and thousands of choices, would begin to single out certain things that were important to her. So someone might not take the time to investigate the code, whereas another person might, and the computer could help facilitate what is revealed by that. The interesting question also is: Why don't I just, instead of offering the lines of code, provide what the code does? That's what Harry Potter does: we see what the spell does, we don't get to know the kind of the articulate magic that's supposedly going on. Because really, as important as the results are, they're irrelevant if you really don't know how that kind of life arises.

It is by refusing to understand those kinds of processes that people get into trouble. It's where superstition comes from, racism, it's all the many problems that are currently plaguing my country. There has been just a simple denial of the necessary science that is behind the biological 
successes that we have in medicine, or the digital successes ... that people can simply put all of that aside in the name of religious claims that simplify the world. You probably had the same experience when you took math at the early grades: there was a way of just learning how to answer the problem. You just plug in A and plug in B and you get an answer. But you really didn't understand what was going on until you proved the theorem that resulted in that equation, in that proof. The Familiar is very much involved in that. It is for advanced readers. It is for readers who are strong and want to go beyond just the sort of razzle-dazzle, show me [only] the consequences of this. They want to understand the tinier aspects because that ultimately makes the reader stronger and more in possession of their imaginative faculties.

KD: That goes back to what you were saying earlier about how you're placing what some would call unreasonable demands on our time, that you're looking for readers who are going to put in the work. I don't know to what extent this came as a surprise to you-but with House of Leaves there was this huge online following on the forum. I was part of it at the time. But now I think to a certain extent some of the aspects, especially of The Familiar, seem to set up not just a single reader willing to put in the time, but also kind of a community of readers, some of whom might be able to speak Singlish and others who speak Spanish, and others who understand the code, and who will all work this out together...

IV: A collective intelligence.

KD: As a kind of hive mind, yes.

MZD: I'm curious about your experience. Have you read the three volumes that are out? Did you read the third more quickly than the others?

IV: Yes, I did. Then I reread it immediately, and I did the same with the first two volumes. Because I could only see where it was going after I had finished it.

MZD: I always have to ask this question just to fact-check myself, because my claim is that the book itself begins to move toward an orb-like transparency, to use a metaphor or a trope from the book itself. For people who read the first one, it's too opaque, too nonsensical. But then, as you move further and further along, the form itself begins to vanish. It becomes less significant. And, getting back to what you said, it's more the subtle moments that begin to create the active experience. We can look all we want at the champagne bottle-the bottle's important, but in the end 
we're going to dwell more on the smell and the size of the bubbles and the fizz and all of that experience that we can actually take in.

It will be interesting to see what the collective experience is of The Familiar and how far I'll even get. I feel happy and content and excited by the prospects of actually bringing season one to a close with volume five, which is where I'm at right now. Even though I knew what was going to happen years ago I'm still intensely thrilled by the experience that I have had this last week as Xanther finally arrives at the name for the cat. And the circumstances by which that happens and how that begins to then bring at least in some way a kind of conclusion to this arc of naming and the significance of what names are. In some way we could look at it more broadly in terms of a certain type of language being a certain kind of naming. Whether it names creatures or the functionality on a computer or, you know, just the various habitats that we surround ourselves with or our various aggressions or fealties. These are all important. And when that choice is made, what are the ramifications?

I think one of the things about House of Leaves, or any book for that matter, is that when you finish reading it, you feel a certain amount of confidence, pride, and even a kind of peace in that this experience has been settled simply by reaching an endpoint, whether you understand it or not. House of Leaves, along with all my work, destabilizes that, which I think is what keeps the forum alive.

Yet, the tricky thing — and I'm curious what you think - is that The Familiar won't grant that conclusion for over ten years, if it's successful. How does that affect a community? In some ways it can become very much about anticipation, that's one conversation: What will happen next? But in some ways it deters interpretation because there's always the threat that what comes next will derange whatever the latest theory is. It really raises the bar on your interpretative skills. If you're a good reader and a good analyzer you'll realize that you have to create an analysis that is not contingent on what happens next.

Which is a life problem, by the way: if we constantly want to view our lives in terms of how we will end our lives this is a very foolish direction. And yet most of us practice it. How do we actually make sense and meaning and find good will in our lives as we are now, and not predicate all of this existence on what's going to happen next. That becomes problematic. That creates causalities that can range from the dictatorial 
control of authoritarian systems or the capitalist desire for growth. All of these can be larger problems that can stem from, believe it or not, a certain type of reading and a certain type of analysis of that reading. So why not create a form of reading that actually, as it goes deeper and deeper and seems to approach a kind of stillness, can create for the reader a kind of transparency, whereby the reader can actually enjoy what's happening now, and not keep propelling him or herself into a nonexistent future.

IV: The pleasure of interminable delay in storytelling is of course at least as old as Scheherazade. It also makes me think of nineteenth-century novelistic conventions of digression and the textual aside. In my research, I have described digressions in contemporary novels as devices that ward off the novel's death (cf. van de Ven 2018). But, when it comes to forms of serial storytelling, a parallel between The Familiar and another medium presents itself: after all, we are currently experiencing the so-called Golden Age of television. To what extent do you think we might be overly familiar with this kind of experience because of television series like Mad Men or Game of Thrones? Do you think that we are trained in this kind of reading or interpreting without an apparent end in sight, by watching TV series that go on for ten seasons? (cf. van de Ven 2016).

MZD: One of the great things about a story or a novel or even a thought is that it presents something that we at least momentarily accept as complete: It finds an argument, it resolves an argument, at least in its shape. And that remains a challenge for me. I believe that all of the volumes could be read independently of one another and enjoyed for what they offer. A quick way of looking at that is seeing what people quote from the book. They find meanings in the book that aren't necessarily tied directly to the narrative. They find meaning in the relationships between the characters and those directions.

But I think the great thing about academia is that it's not a moribund practice. The institutions live because what's brought to life there is not dead. We constantly need to revisit and revise how we teach reading and how we read ourselves. And I think we're all, all three of us, privy to the experience. After all, the way I read differs simply by how old I am. It is very much like a music critic or a musician who becomes overly aware of how one song is so derivative of another, whereas a young kid wouldn't recognize that song. They experience that song as vital and new, and yet we hear that song or read that book and know, "Oh wait a minute, I know 
exactly what this structure is. There's going to be a couple of variations that briefly intrigue me, but that's it." Through my readers, and certainly when I go out on tour and I interact with a lot of young people, I can at least gauge what their experiences are and you can do the same with students.

KD: I want to ask about the cats. Earlier, you referred to the book as a cage. And inside the cage, it seems to me, is obviously a cat-whether it's a domestic cat or a panther. In one of the appendices to House of Leaves there's the poem "The Panther" (2000, 559-60) which revolves around the figure of the cage and the panther's restless circular pacing behind the bars-in an obvious nod to Rilke's "Panther," and, given that the poem also raises the problem of the name, perhaps also Borges's "Other Tiger" (cf. 2000, 313). At any rate, now, sixteen years later in The Familiar, we have Xanther, who, I assume, is also kind of a Panther $+x$.

And so, on the one hand, these feline presences seem to exert an influence on your work, or perhaps rather provide a kind of impetus for it. This was very obvious when The Familiar was first announced on the forum and all it said was that it would be about "a 12 year old girl who finds a kitten" (Hazel 2010) and that it would be twenty-seven volumes. We all thought: How can you possibly write twenty-seven volumes about that? Since then it's become clear that each volume is going to be 880 pages long, so if you keep this up the whole thing will run to well over 20,000 pages. That's got to be some kind of record. But somehow the sheer magnitude, the monumentality, of this project seems incommensurate with the premise-and this is obviously deliberate. At the same time, at the center of all of this book presence that you're producing, these twenty-seven volumes, there is, as you yourself put it, also a particular feline absence. And this is an absence that has been there since House of Leaves as well (I'm thinking of Zampanò, who is surrounded by all these cats who then gradually disappear). So I guess the question is: What's up with the cats? Or more to the point: What is the relationship, for you, between book presence and feline absence? MZD: Well, I love cats obviously. I have two great cats. Beyond that, it becomes incredibly complicated. And I even allow a randomness there. I love horses and dogs and all those kinds of distinctions are fascinating to me, but why I happen to ultimately settle on a cat is, you know, a result of coincidence, luck, affection, born out of my own sort of familial experiences with the animal and so on. On a literary level it's hard to 
resist a cat that is in miniature, in a way, that we just don't experience with any other sort of animal. This tiny little creature that can sit in your palm and yet demonstrates almost the same kind of behaviors as a 1,200 lbs. Siberian tiger. It's that image of how symbolically something can be stretched. Victor Hugo's friend said, "God created the cat so that men might pet the tiger." And that's one aspect of it.

And then of course you have something that is carnivore, that's a predator. You have something that constantly displays ludic behavior in your living room, chasing after little pieces of paper or running after a fallen acorn or whatnot. ... So, as a topic it's enormously rich. Yet it's not in any sense original, especially if one considers the tradition, which I am aligned with, of Melville's obsession with various aspects of the whale, or Thomas Pynchon's obsession with the V2 rocket, or Joyce's obsession with the city. It's that kind of belief in detail. To me, the literary field is a quantum field. It is the belief that by looking at the atomic fizz of letters and words, these tiny variations have enormous consequences. The generalities of different forms of fiction, this atomizing of fiction, is very important.

What I love, in season one, volumes one through five, is just the presence and non-presence of the cat. The fact that it's clearly there, it's clearly affecting Anwar, Astair, Xanther obviously, Jingjing, and Tian Li. There are rumors of cats and other characters that are coming in, and we feel the presence of something and we're not entirely sure what it is. Now, from a narrative point of view, I do hold a lot of the cards. I know that I've mapped out the story from beginning to end. On the spine you can see literally the figure of a cat beginning to emerge. The tail is beginning to manifest itself, so we are at the start of the tail [tale?] graphically. We are alerted to that fact. You never want to grab a tiger by the tail. So there's already a physical game that's being played with the text itself.

But as soon as we have this graphic imposition on the spine, on the spines of the book, on the covers of the book, that begin to denote what this is, we also have a curious absence. We have a cat that refuses to interact, really, beyond so much as a purring or maybe a squeak, but it seems to be dying, really, and it possesses almost no space, except in terms of the psychic space of the characters. In that respect, I regard the book literally as the familiar of the reader and as a familiar to the writer. In order for me to tell the story, as much as I may have mapped out where it's going, it requires the participation, as alchemical as that is, with readers. Because, as the cat comes to life, the cat will begin to acquire the puissance of its readership. 
And this is the story that I always set out to write, it wasn't the ego trip of Only Revolutions - the literal ego trip, the literal critique of the ego trip. This is very much the tail/tale of a cat, of our tale. How do we begin to create this story, you know? Sometimes it's as literal as a reader saying, "You should read this book," or "Have you seen this?" Sometimes it's a lot more collective: "What is Mefisto doing?" or "What exactly is happening in the forest?" and "What are those blood spreads?" etc. Then there's the larger marketplace, the larger global environment of how a book like this can survive.

So, in some ways - and this gets back to the question of the expectation at the end versus knowing the end-the presence and the absence of the cat is very much the thesis of the twenty-seven-volume subject. You are positing the main concern and that's what comes to an end in the end of [volume] five. But now, in volume six, the central question is: How will this cat begin to interact? And that will very much be influenced literally by how I see that cat interact in your lives, in the lives of other readers. What will be the result, as readers gather to this-or don't? How will that help shape this creature? And that's the exciting part. Because we don't know. ${ }^{7}$

\section{Notes}

1 Cf. Jessica Pressman's interview with Doug Beube and Brian Dettmer in this book. -Ed.

2 Danielewski uses the term "signiconic" (e.g., 2015a, 33) in reference to representations that combine text and image in order to "achieve a third perception no longer dependent on sign and image for remediating a world in which the mind plays no part" (Danielewski 2015b).

3 Danielewski's consistent use of the first-person plural "we" points to the collaborative aspect of the production of his works. In the case of the e-book of Only Revolutions, this includes a team of designers, the digital production group at Random House led by Liisa McCloy-Kelley, and pianist Christopher O’Riley who composed the musical score. In The Familiar, this sense of multiple authorship is also evidenced by the "credit sequence" at the end of each volume, which includes references to several translators and a design team (Atelier $\mathrm{Z}$ ) and production company (Circle Round a Stone).

4 During the interview, we had experienced various technical difficulties, particularly with the sound. 
5 "Narcon" is short for "Narrative Construct": In The Familiar, the Narcons are mysterious intervening entities that can pause the narrative and comment on it. They consist of "nothing but numbers. Zeros and ones" and are "fractally locatable" (Danielewski 2015a, 565). They are programmed (though it remains unclear by what or whom) and operate according to a number of prescribed parameters.

6 Cf. Kiene Brillenburg Wurth's contribution to this book. -Ed.

7 In early February, 2018, Danielewski announced on social media that the Familiar has been paused, owing to insufficient reader numbers "to justify the cost of continuing."

\section{Works cited}

Carrión, Ulises, 1980. “The New Art of Making Books.” In Second Thoughts, 6-22. Amsterdam: VOID Distributors. https://monoskop.org/log/?p=14521

Danielewski, Mark Z., 2000. House of Leaves. New York: Pantheon Books.

Danielewski, Mark Z., 2006. Only Revolutions: The Democracy of Two. Set Out \& Chronologically Arranged. New York: Pantheon Books.

Danielewski, Mark Z., 2015a. The Familiar, Vol. 1: “One Rainy Day in May.” New York: Pantheon Books.

Danielewski, Mark Z., 2015b. “The Familiar, Volume 1 Reader’s Guide.” http://www. penguinrandomhouse.com/books/213605/the-familiar-volume-1-by-mark-zdanielewski/9780375714948/readers-guide/

Danielewski, Mark Z., 2015c. Only Revolutions: Interactive eBook. Knopf Doubleday Publishing Group. iOS 4.3 or later; Mac OS X 10.9 or later. https://itunes.apple.com/ us/book/only-revolutions/id422526207

Danielewski, Mark Z. (@markdanielewski), 2018. "It is with a heavy heart that I must report THE FAMILIAR has been paused." Twitter, February 2, 10:19 AM. https:// twitter.com/markdanielewski/status/959491469235994628

Hazel. 2010. “At Least This Explains All the Cat T-Shirts.” MZD Forums, September 15, 3:50AM. http://forums.markzdanielewski.com/forum/the-familiar/the-familiaraa/5860-at-least-this-explains-all-the-cat-t-shirts\#post5860

Rich, Motoko, 2006. "Digital Publishing Is Scrambling the Industry's Rules." New York Times, June 5. http://www.nytimes.com/2006/06/05/books/05digi.html van de Ven, Inge, 2016. "The Serial Novel in an Age of Binging: How to Read Mark Z. Danielewski's The Familiar. " Image \& Narrative 17 (4): 91-103. http://www. imageandnarrative.be/index.php/imagenarrative/article/view/1339 van de Ven, Inge, 2018. “Size Matters: Karl Ove Knausgård’s Min Kamp and Roberto Bolaño's 2666 as (Anti-)Monumental Novels." In Materializing Memories in Art and Popular Culture. Edited by László Munteán, Liedeke Plate, and Anneke Smelik, 106-22. London: Routledge. 